\title{
Students' Perception of Acquisition of Personal Health Skills among Adolescent in Imo State through the School Health Programme
}

\author{
Anthonia U. Ejifugha, PhD \\ Department of Physical and Health Education \\ Alvan Ikoku Federal College of Education, Owerri-Nigeria \\ Akhire Ibhafidon PhD \\ Department of Physical and Health Education \\ Alvan Ikoku Federal College of Education, Owerri-Nigeria
}

Doi:10.5901/ ajis.2014.v3n7p153

\begin{abstract}
The purpose of the study was to identify students' perception of acquisition of personal health skills among adolescents in Imo State through the school health programme. Six research questions and five hypotheses guided the study. The descriptive research design was adopted for the study which utilized 360 students in secondary schools in Imo State as the sample frame through multi stage sampling procedure. A questionnaire was the main instrument for the study. The mean, standard deviation, t-test, ANOVA and Duncan Multiple range test were used for data analysis. The result of the study revealed that the students perceived all the health skills as very important; these encompass health practices for body hygiene, clothing and physical exercise $(\bar{x}=2.50)$. Gender, educational qualification of parents and person responsible for health care were significant on the acquisition of personal health skills. Family typology and type of single parenthood were not significant on acquisition of skills for personal health. It was recommended that personal health skills should be taught as component of life- long education. Male students should be taught to realize that personal health skills are for optimal health and not for beauty. Parents should be made to realize through the Ministries of Education and Health that their educational qualification and their responsibility in family health care significantly influence the acquisition of personal health skills of adolescents.
\end{abstract}

\section{Introduction}

Maintenance of optimal personal health has always been a challenge to adolescents in schools in Nigeria. Well groomed adolescents, whose knowledge of personal hygiene taught in school and reinforced by their homes, demonstrate a high level of personal cleanliness. Most often decent clothing is not synonymous with optimal body hygiene which is an aspect of personal health. Skill-based personal health is needful in this civilized era, which is acquired not just for looking good but as a way of life. Just as acquisition of life skills is a continuous process so is acquisition of personal health skills. Acquisition of personal health skills is significant for optimal health. Adolescents need to identity, acquire and adopt personal health skills as a way of life. This study seeks to present personal health skills perceived by adolescents and factors that influence them.

Personal health has been described as that component of physical health which is primarily concerned with the means and procedure by which the human body is kept at its optimal performance (Windy, 2002). Personal health is fundamentally individualistic. It is concerned with an individual's social, physical, mental, and emotional wellbeing.Knowledge of personal health is demonstrated in the effective practice of personal health skills and good health habits (Onuzulike 2002). Personal health is the overall health status of the body and mind. It is the effort made by an individual to keep his body and mind performing optimally (Oparah, 2011). It encompasses the physical, social, emotional and mental dimensions of an individual's health. It depends comprehensively on the active, and passive activities people engage in to promote personal health. These include:

- personal actions for preventing or minimizing the effect of a disease,

- personal hygiene practices to prevent infection and illness,

- social structure of the individual's personal life that influence personal relationship volunteering, and other social activities (Wingard, 1982),

- proper emotional disposition and mindset in addressing every situation that may come up as life challenges 
and physical fitness to meet ones daily tasks.

Practically, personal health encompasses dressing and clothing, physical fitness, rest and exercise, use of cosmetics, oral hygiene, body hygiene and hair care. Maintenance of these demonstrates the personality of the individual in the acquisition of personal health skills.

Health skills have been defined as specific tools and strategies that lead to better and more informed choices which help an individual to become and remain healthy (Edward, 2003). Skill is interchangeably used with concept such as competence, interventions, and techniques (O' Hagen, 1996). It is a series of physical and mental acts executed for the purpose of demonstrating complete control of the act by the executor. Skills are built on experience and practice. A skill denotes cognitive and manipulative abilities coupled with experience in doing things. Skills are gradually learnt through experience (Trevithick, 2011). Skill acquisition is a specific form of learning. It refers to a prolonged learning about a family of events. It involves the paring of similar stimulus with a particular request. With it one can develop knowledge of how to respond to certain situations, behaviours that encompass all behaviours that are learned and can be refined with practice given the right condition (Speelman, 2005).

Health skills are human activities that are learned and are developed through experience. They promote physical, mental, emotional and social well being. They are integral part of life skills aimed at maintaining optimal health. Health skills are specific tools and activities that lead to better and more informed choices which help one to become and stay healthy. They are very necessary to achieve wellness and can help an individual get rid of unhealthy behaviour. (Webmaster, 2013). They are specific strategies that help one to maintain, improve and protect all aspects of health (WHO/GP 1992).

Perception is the process by which people translate sensory impressions into coherent and unified information. Perception is equated with reality for most practical purposes and guides human behaviour in general. It helps make up our conscious experience and allow us to interact with the people and objects around us (Snowdon, 1998).

William Kane illustrated the wheel of comprehensive school health programme that utilizes health education, health services and healthful school living. The learner is the focus of health education in the classroom, school, home, and community (Aspungh and Ezell, (2011) in Onwuama (2012). Collaborating with Hamilton-Keke (2012) who advocated holistic school health programme, Onwuama (2012) concurred also with Aspaugh and Ezell who are proponents of comprehensive school health programme. Though these scholars are advocates of comprehensive school health programme, this study advocates creation of awareness among students and sensitization of teachers and principals to shift base from acquisition of health knowledge to acquisition of health skills. The latter obviously transcends the former.

The Nigerian Education Research Development Council (NERDC 2008) maintained that the philosophy of the new Basic Education Curriculum in Nigeria states that the learner who has gone through nine years of basic education should have acquired appropriate levels of literacy, lifelong skills, as well as moral and civil values needed for social foundation of lifelong learning as a basis for scientific and reflective thinking. Skills for health are integral components of life-long skills that substantiate the need for skill-based health education and school health programmr at least at the junior basic schools in Nigeria.

\section{Statement of the Problem}

Health education in Nigeria has not been skill-based but rather knowledge-based with emphasis on acquisition of health habits. Skill acquisition in any facet of human endeavour makes life easier than it used to be. It saves time, money, and makes the individual confident in handling related situations. It is teacher-oriented and learner-based. One major weakness of health education in Nigeria is acquisition of health knowledge devoid of health skills among adolescents in Imo State. The proliferation of preventable health problems among adolescents in Imo State could be attributed to their inability to develop health skills in personal health matters.

The Partnership for $21^{\text {st }}$ century skills advocated adoption of local, state, and federal policies that support skills in structure for all students (Lai and Viering, 2012). This development coupled with WHO's call for skills-based health education (WHO, 2009) motivated the researchers to address the obvious absence of skill-based health education in schools and particularly in personal hygiene and emphatically body hygiene among adolescents. The study is delineated to body hygiene, dressing, and exercise as an aspect of personal health.

The purpose of the study is to determine students' perception of skills for health to be acquired in personal health among adolescents through te school health programme in Imo State. The study will identify personal health skills to be acquired among adolescents. It determines whether gender, family typology, status of single parenthood, educational qualification of parent and person responsible for family health are significant on the acquisition of personal health skills. 


\section{Method}

To achieve the purpose of the study, the descriptive survey design was used. Gall and Borg (2007), stated that the design in its most basic form involves the description of natural and man- made phenomena; their forms, action, change over time and similarities with other phenomena. Imo State was the focus of the study, since majority of adolescents in the state were in schools. The population of the study covered all public schools in Imo State. The multi-stage sampling technique was used to draw a sample size 565 students in schools where health education was taught as a subject in Imo State. A fourteen-item questionnaire was developed with focus on body hygiene, from WHO document on skills for health. The instrument was validated and the reliability co-efficient was 0.94. Descriptive and analytical statistics were used for data analysis. The mean, standard deviation, t-test Duncan multiple range t-test, and ANOVA were used for data analysis. Items that fall within 2.50-3.00 were rated to be very important.

\section{Results}

\subsection{Research Question 1}

What is students' perception of the skills for health to be acquired in Personal Health through school health programme? Data answering this research question are contained in Table 1

Table 1: Personal Health skills

\begin{tabular}{lccc}
\hline Skills in Personal Health & $\bar{X}$ & SD & Decision \\
\hline 1. Regularly wash clothes and hair & & & \\
2. Regularly wash hands e.g. after toileting, and eating. & 2.84 & 0.38 & very important \\
3. Brush teeth with tooth brush after breakfast and dinner. & 2.72 & 0.34 & very important \\
4. Cutting of finger and toe nails regularly & 2.72 & 0.50 & very important \\
5. Regularly shave hairs around the armpit, & & & \\
pubic region and face. & 2.75 & 0.47 & very important \\
6. Wash clothes and iron regularly. & 2.68 & 0.49 & very important \\
7. Wash under wears regularly (e.g socks, pants, singlet). & 2.87 & 0.36 & very important \\
8. Engage in regular physical exercise & 2.81 & 0.46 & very important \\
9. Change menstrual pad often to avoid emission of odour. & 2.87 & 0.38 & very important \\
10. Take bath twice a day (moming and night). & 2.82 & 0.40 & very important \\
11. Cover the mouth and nose when sneezing/coughing. & 2.84 & 0.41 & very important \\
12. Clean the anus thoroughly after defecation. & 2.85 & 0.38 & very important \\
13. Disposal of tissue paper properly after use. & 2.79 & 0.49 & very important \\
14. Avoidance of nose picking. & 2.61 & 0.60 & very important \\
Grand X \& SD & $\mathbf{2 . 7 9}$ & $\mathbf{0 . 2 6}$ & very important \\
\hline
\end{tabular}

Table 1 shows a grand mean score of 2.79 (with SD of 0.26 ) which falls with between $2.50-3.00$. The Table further shows that all the 14 skills in personal health had mean scores ranging from 2.54-2.90 which fall between $2.50-3.00$. This implies that students perceived all the personal skills as very important for the acquisition of skills for health. The table also shows that the standard deviation values which range from 0.34 to 0.60 are not close together, implying students responses are far apart.

\subsubsection{Hypothesis 1}

Gender does not have significant effect on students' perception of health skills to be acquired in Personal Health. Data testing this hypothesis are contained in Table 2 
Table 2: Two Sample t-test for the Effect of Gender on Students' Perception of Health Skills to be Acquired in Personal Health

Two Sample t-test for the Means of unit_area_2 within gender

Sample Statistics

\begin{tabular}{lcccc}
\hline Group & $\mathrm{N}$ & Mean & Std. Dev. & Std. Error \\
& & & & \\
\hline female & 285 & 2.84 & 0.23 & 0.0137 \\
male & 280 & 2.73 & 0.27 & 0.0166
\end{tabular}

Hypothes is Test

\begin{tabular}{lccc}
\hline If Variances Are & t statistic & Df & Pr $>$ t \\
\hline Equal & 5.100 & 563 & $<.0001$ \\
\hline
\end{tabular}

Table 2 shows that the mean scores for female is slightly higher than that of male students, on students' perception of health skills to be acquired in personal health, as 2.84 and 2.73 , respectively. This implies that of female and male students perceived the health skills to be acquired in personal health through to be very important.

Furthermore, the Table gives the t-calculated value for the mean differences as 5.10 with a significance probability of $<0.0001$, which is less than 0.05 . Thus the test is significant at $5 \%$ level of significance. We, therefore, conclude that gender has a significant effect on students' perception of health skills to be acquired in Personal Health.

\subsubsection{Hypothesis 2}

Students' family typology does not have any significant effect on students' perception of health skills to be acquired in Personal Health. Data testing this hypothesis are contained in Table 3

Table 3: Two Sample t-test for the Effect of Family Typology on Students' Perception of Health Skills to be acquired in Personal Health

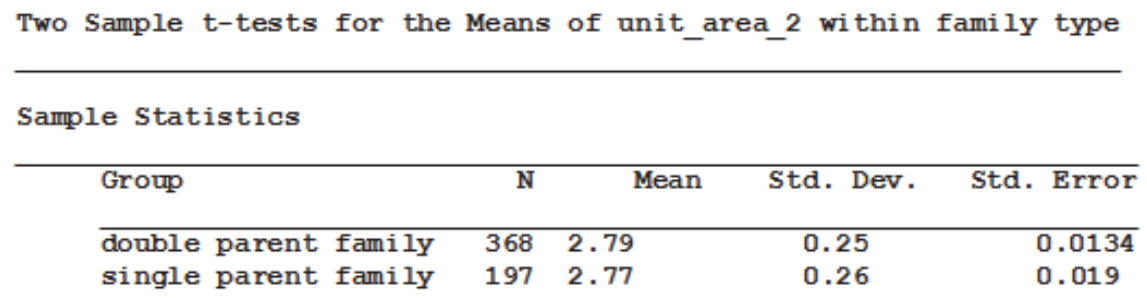

Hypothesis Test

\begin{tabular}{lcrr}
\hline If Variances Are & t statistic & Df & Pr $>$ t \\
\hline Equal & & & \\
Not Equal & 1.003 & 563 & 0.3161 \\
& 0.992 & 388.33 & 0.3216 \\
\hline
\end{tabular}

Table 3 shows the mean scores for students with double parents $\left(x^{\bar{x}}=2.800\right)$ is slightly higher than that of the single parent family typology, $\left(x^{-}=2.78\right)$ This implies that students' perceived personal health skills as very important.

Furthermore, the Table shows the t-calculated value for the mean differences is 1.003 with a significance probability of 0.3161 , is greater than 0.05 . Thus the test was not significant at $5 \%$ level of significance. We, therefore, 
conclude that students' family typology does not significantly affect students' perception of health skills to be acquired in Personal Health. This implies that the perception of the students with double parent family typology was the same as those as of students with single parent family typology, in terms of health skills to be acquired in Personal Health.

\subsubsection{Hypothesis 3}

Students' perception of health skills to be acquired in Personal Health is not significantly affected by status of single parenthood. Data testing this hypothesis are contained in Table 4

Table 4: ANOVA for the Effect of Status of Single Parenthood on Students' Perception of Health Skills to be acquired in Personal Health

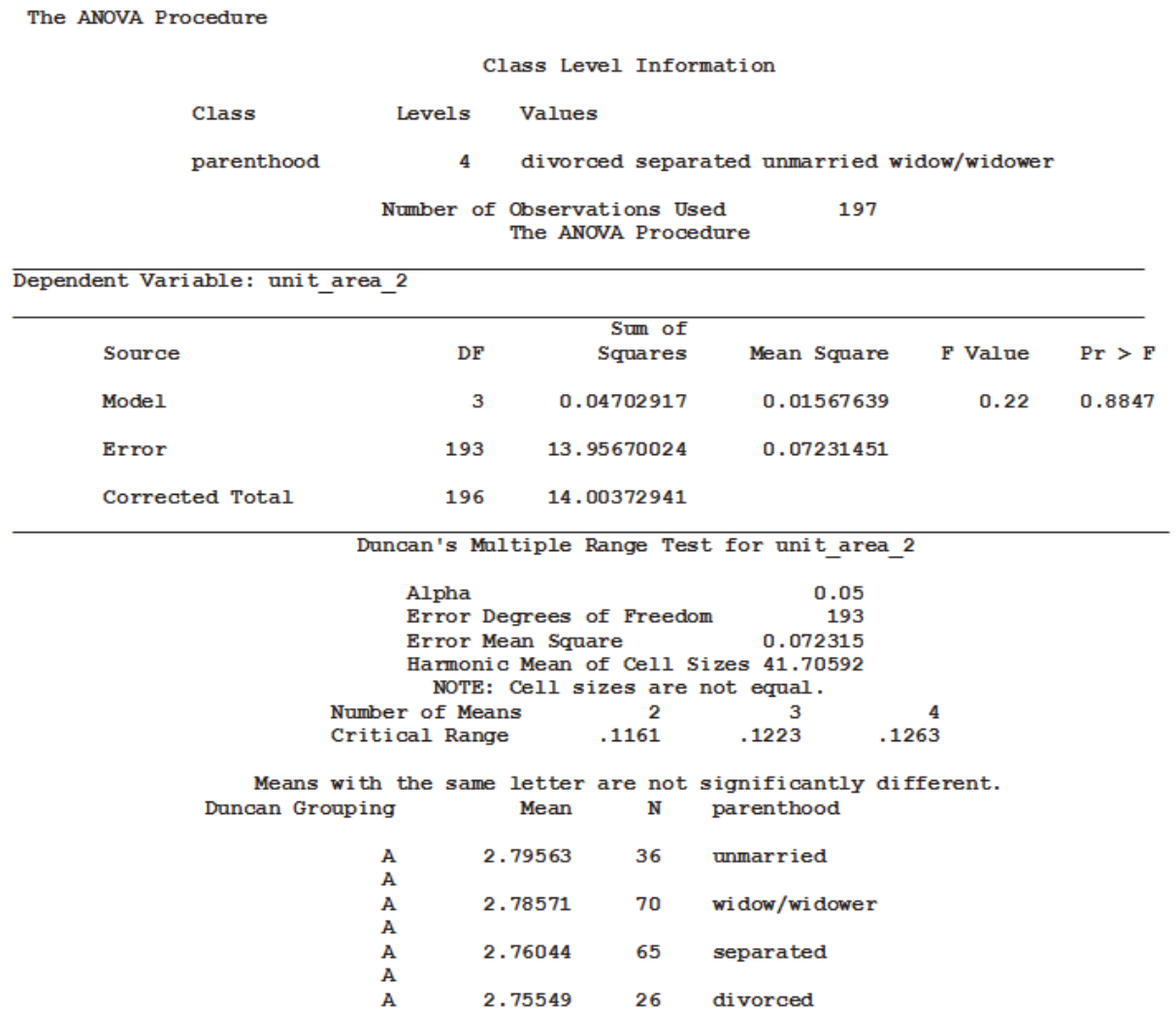

Table 4 shows that students, whose single parents were unmarried $\left(x^{-}=2.80\right)$ had mean score that is slightly higher than those students whose single parents are widows or widowers $(\bar{x}=2.79)$, and those students whose single parents were separated $(x=2.76)$. and students whose single parents are divorced $(x=2.755)$. These mean that students perceived these personal health skills as very important.

Furthermore, the Table gives the F-value for the mean differences as 0.22 with a significance probability of 0.88 , which is greater than 0.05 . Thus the test is not significant at $5 \%$ level of significance. We, therefore, conclude that students' perception of health skills to be acquired in personal health through school health programme is not significantly affected by status of single parenthood. This is confirmed by Duncan's multiple range test, which assigned the same Duncan's grouping letter, A, to each of the four status of single parenthood, indicating no significant differences among the various status of single parenthood.

\subsubsection{Hypothesis 4}

Students' perception of health skills to be acquired in Personal Health is not significantly influenced by the educational qualification of parents. Data testing this hypothesis are contained in Table 5. 
Table 5: ANOVA for the Effect of Educational Background of Parents on Students' Perception of Health Skills to be acquired in Personal Health

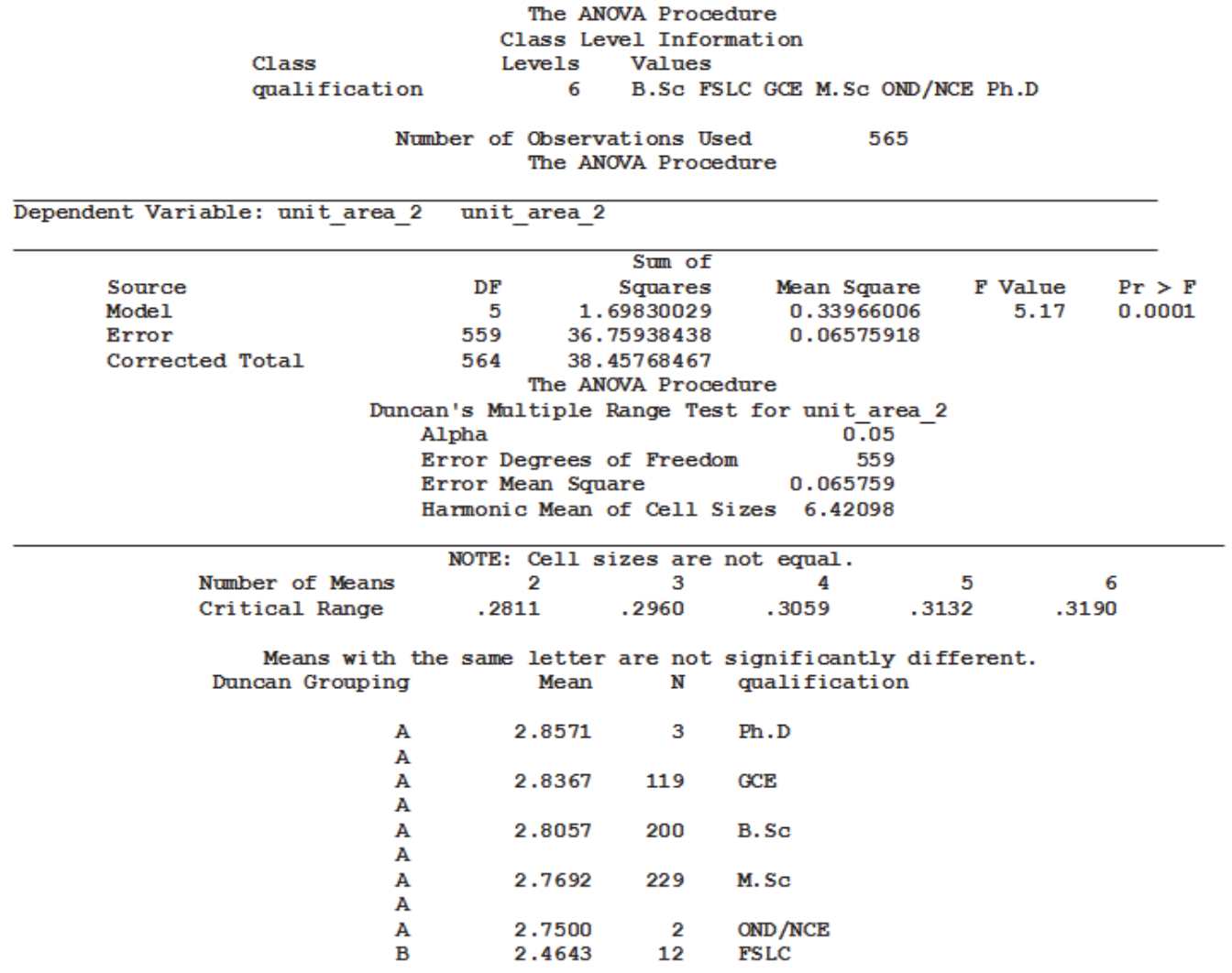

Table 5 shows that students whose parents hold a Ph.D. degree $\left(x^{-}=2.85\right)$ have mean score slightly higher than students whose parents hold GCE $\left(x^{-}=2.84\right)$, B.Sc degree $\left(x^{-}=2.81\right)$, M.Sc degree $\left(x^{\prime}=2.77\right)$, OND/NCE $(\bar{x}=2.75)$. and parents with FSLC $(x=2.46)$. These students' whose parents have these educational qualifications perceived health skills as very important. Students whose parents hold FSLC perceived these skills as important. Furthermore, the Table gives the Fvalue for the mean differences as 5.17 with a significance probability of 0.0001 , which is less than 0.05 . Thus the test is significant at $5 \%$ level of significance. We therefore conclude that students' perception of health skills to be acquired in Personal Health through school health programme is significantly influenced by the educational qualification of parents. The Duncan's multiple range t-test reveals that:

(a) The perception of students whose parents hold a Ph.D. degree is significantly higher than that of those whose parents hold FSLC, in terms of students' perception of health skills to be acquired in Personal Health, since the two groups of students have different Duncan's grouping letters, A and B, respectively.

(b) The perception of students whose parents hold GCE is significantly higher than that of those whose parents hold FSLC, in terms of students' perception of health skills to be acquired in Personal Health, since the two groups of students have different Duncan's grouping letters, A and B, respectively.

(c) Similarly, significant differences in the perception of other pairs of groups of students with different parental educational qualifications exist if the students' groups have different Duncan's grouping letters. Otherwise, no significant differences exist.

\subsubsection{Hypothesis 5}

The person responsible for family health care does not significantly contribute to students' perception of health skills to be acquired in Personal Health Data testing this hypothesis are contained in Table 6 
Table 6: ANOVA for the Effect of Family Health Care Provider on Students' Perception of Health Skills to be acquired in Personal Health

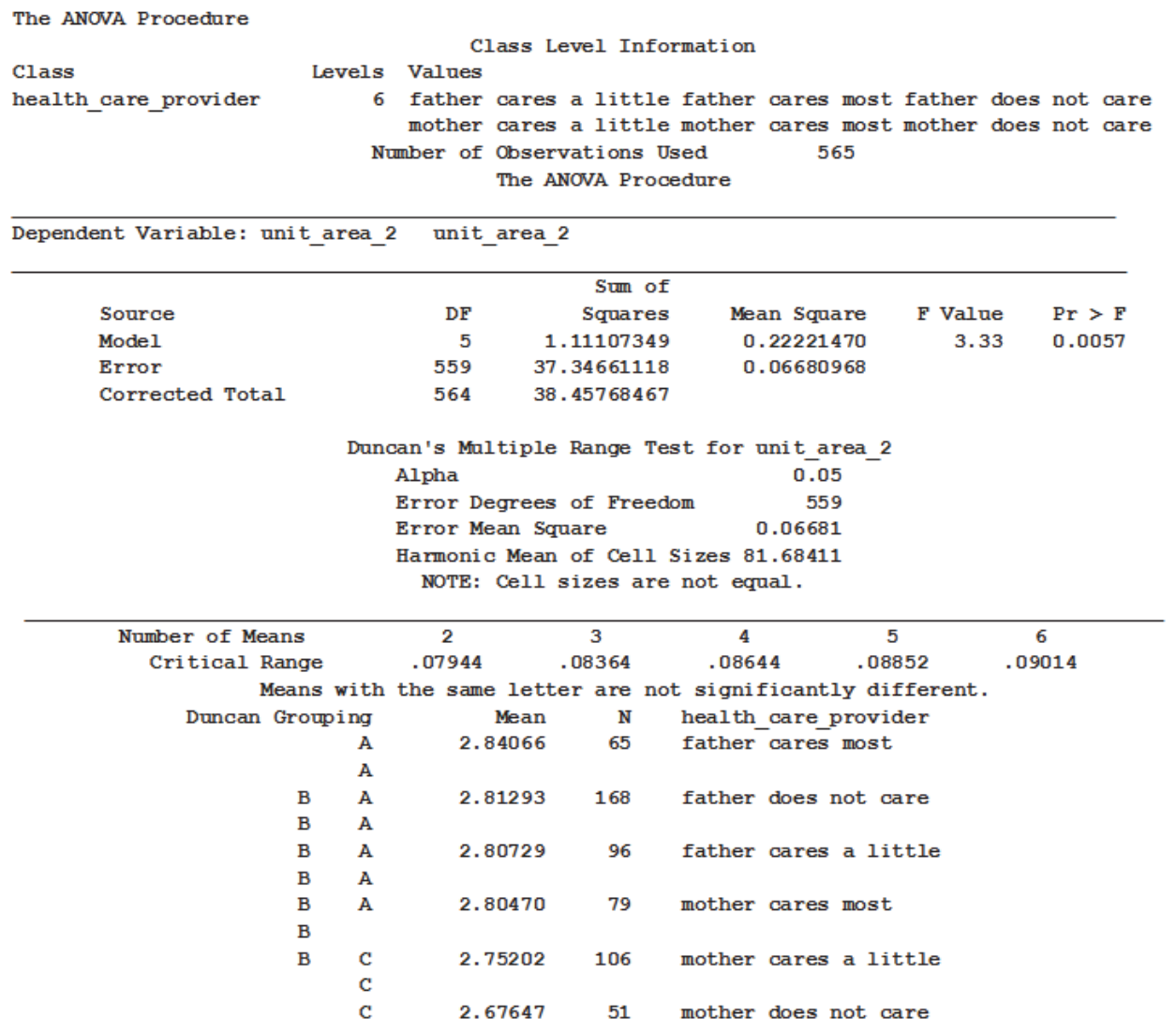

Table 6 shows that students, whose fathers care most $\left(x^{-}=2.84\right)$ have the highest perception of health skills to be acquired in Personal Health. This is followed by students whose fathers do not care $(\bar{x}=2.81)$, and whose fathers care little $(\bar{x}=2.81)$, whose mothers care most $\left(x^{-}=2.81\right)$, and students whose mothers care a little $\left(x^{-}=2.75\right)$. Students, whose mothers do not care $(\bar{x}=2.68)$ have the lowest perception of health skills to be acquired in Personal Health. This implies that the perception of students on the person responsible for health care with regard to skills to be acquired in personal health indicates the skills to be very important.

Furthermore, the Table gives the F-value for the mean differences as 3.33 with a significance probability of 0.0057 , which is less than 0.05 . Thus the test is significant at $5 \%$ level of significance. We therefore conclude that the person responsible for family health care significantly contributes to students' perception of health skills to be acquired in Personal Health through school health programme. The Duncan's multiple range t-test reveals that:

(a) The perception of students whose fathers care most is significantly higher than that of those whose mothers do not care, in terms of students' perception of health skills to be acquired in Personal Health, since the two groups of students have different Duncan's grouping letters, A and C, respectively.

(b) The perception of students whose fathers care most is significantly higher than that of those whose mothers care a little, in terms of students' perception of health skills to be acquired in Personal Health, since the two groups of students have different Duncan's grouping letters, A and B, respectively.

(c) Similarly, significant differences in the perception of other pairs of groups of students with different family health care providers exist if the students' groups have different Duncan's grouping letters. Otherwise, no significant differences exist.

\section{Discussion}

Students perceived all the skills in personal health as very important $(\bar{x}=2.79)$ for the acquisition of skills for personal 
health (Table 1).The result of the study was actually expected. For insttsance, frequent physical activities boost the immune system and help prevent diseases, cardiovascular disease, type 2 diseases and obesity. It promotes mental activities, helps prevent depression and promotes self esteem and body image Ayoade and Blave (2012) seemed to confirm this. It inherently attracts other activities involved in sound personal health because of emission of body waste due to exercises. Explaining the need for acquisition of motor skills as a personal health skill while in school, Lawson (1977) in Amaechi (1997) stated that simple balance and movement skills combine into more complex skills in posture and the numerous body control activities to enhance physical activities.

Clothing is won to protect the body against weather conditions, beautify the body and communicate the taste of the wearer to the public. (Omavowere and Gloria, 2011). Dressing indicates whether an individual is conservative, progressive, out-going or reserved, careless or organized, a leader or a follower, confident or insecure (Esionwu and Igbo, 2008) in (Omavowere and Gloria 2000). Ahia (2001) substantiated that apart from personal identification, clothing serves the purpose of group identification, gender stereotyping and status symbolization. Clothing is not just putting on a sown material to cover ones nakedness, clothing is skill-based and skill oriented to meet the taste of time. Weather demands it for keeping the body comfortable. These authors corroborate that dressing is a personal health skill which confirms the result of the study.

Clothing and physical exercises all buttress the need for acquisition of skills in personal health. What used to be taught as personal health habits have turned out to be skill demanding. Even care of finger and toe nails as well as hair care is demanding skills to make them attractive. In view of this, Woody (2001) defined personal health as that aspect of physical health that is concerned with the means and procedure by which the human body is kept at its highest level of efficiency or performance and by so doing bring the human body to the highest level of realization and satisfaction with regular output. Personal health skills are activities that demand continuous improvement and development that enhance the personal output of individuals. Woody therefore by this definition concurred with the result of the study on the need for body hygiene since they demand continuous practice.

The study further revealed that gender and the person responsible for health care in the family were significant while family typology and status of single parenthood were not significant in the acquisition of personal health skills. Duncan test revealed the two independent variables gender and person responsible for health care which were significant in the study. The female gender was more favourable in the acquisition of personal health skills than the male.

The reason for this gender differential may be attributed to the biological constitution of females that make them pay more attention to themselves than their male counterparts. The innate desire to look attractive also contributes immensely to the desire for sound personal health among the feminine gender. Additionally educational qualifications of parents were a significant factor in the acquisition of health skills. Students whose parents have Ph.D. were significantly higher than those whose parents have only First School Leaving Certificate. Likewise the perception of students whose parents hold GCE/WASC was significantly higher than those whose parents hold First School Leaving Certificate (FSLC). This implies that personal health of adolescents was significantly enhanced by parents' educational qualification. The need for social mobility of parents cannot be over emphasized since it positively permeates the diverse aspects of an individual's life and most importantly the health aspect.

\section{Conclusion}

The study sought to identify students' perception of personal health skills to be acquired by adolescents in secondary schools in Imo State. The results of the study revealed a group of activities known as skills for personal health were perceived as very important by students. These skills encompass care of the body, clothing and regular exercise. Gender, educational qualification, and person responsible for family health care were significant on students' perception of personal health skills, where as family typology and of single parenthood were not significant. The study further revealed that the perception of students whose fathers care most was significantly higher than that of those whose mothers do not care, and those whose mothers care a little, in terms of students' perception of health skills to be acquired in Personal Health. Furthermore, the perception of students whose parents hold a Ph.D. degree was significantly higher than that of those whose parents hold FSLC. Furthermore, the perception of students whose parents hold GCE was significantly higher than that of those whose parents hold FSLC.

\section{Recommendations}

The study recommended that teachers should teach and practice personal health skills as life- long skills to be acquired 
by students. Male students should be taught to realize that personal skills are not for beauty but for optimal health. Parents should be made to know through Parents Teachers Association that their educational attainment is positively correlated with acquisition of personal health skills of their adolescents. Father/mother whoever is responsible for family health care should be made to realize that his/her role influences the acquisition of personal health skills.

\section{References}

Ayoede T.O. \& Blawo, J.F. (2012). Physical activity; a road map to promoting good health and wellness in Nigeria. Nigerian School Health Journal 24(1): 41-44

Amaechi, W.N (1997). Movement behaviour in the education of children. Journal of Review in Physical Health Education and recreation (1) $39-45$.

Ahia, C.N. (2001). Effects of economic reform measures in family clothing patters in Nigeria, Journal of Home Economic Research. 3: (1); 46-55.

Edward, A. (2005) The Relevance of health skills among Adolescents in secondary schools. Meaning of Health skills 30 (2), 25-35.

Hamilton -keke J, (2012). Public secondary school management staff assessment of status of health observation, examination and medical history keeping in Yenagoa Bayelsa State Nigerian School health Journal 24 (1) 2012.

Lai, E.R. \& Viering, M (2012) Assessing 21st century skills integrating research findings Canada. National Council on Measurement in Education, Vancouver, B.C. pg 25-28

Omoawere E.O. \& Gloria, L. (2011) Analysis of adult female clothing made with adapted pollen and free hand culture constraint and property. Journal of Educational and Social Research 1 (2): 135-144.

Onuzulike N.N. (2002). Patterns of medical advice seeking behaviours of pregnant woman in Imo State. Ph.D Dissertation, Department of Human Kinetics and Health Education, Faculty of Education, Nnamdi Azikiwe University Awka

Oparah, J. (2012). Cognition of health consequences of tobacco smoking among in-school adolescent in Owerri Metropolis. Nigerian Journal of Health Promotion 2(1); 81-95

Snowdon, P. F. (1998), Strawson on the Concept of Perception, in L. Hahn (ed.) The Philosophy of P. F. Strawson. Chicago and Lasalle: Open Court.,4-7

Trevithick P. (2011). Social work skills: a practice handbook New York Mixed sources

Windy,P. (2002). Personal Health and Hygiene Habits. London: Sphere Books Ltd.

Webmaster (2012). Health skill definition. www.mit.edu/definitions html. Retrieved 13/12/2012

WHO skills for health (skill- based health education including life skills). Information Service on School Health Document 9 